\title{
RADIOTEATRO E O DIREITO DE SONHAR ${ }^{1}$
}

\author{
Vivian de Camargo Coronato² \\ Vera Collaço (orientadora)
}

RESUMO: Neste texto inserido dentro de um Congresso Internacional de Teatro (Teatro do grego theatron = lugar de onde se vê, público) irei tratar de algo que tem como característica a ausência da visualidade: o rádio, mais especificamente o radioteatro.

PALAVRAS-CHAVE: Rádioteatro; Arte Acústica; Definições.

Já há muito tempo que creio, e continuo acreditando, que o rádio é mágico. A televisão não é ruim, mas o rádio é mágico. Se a televisão tivesse sido inventada antes, a chegada da radiodifusão teria feitos as pessoas pensarem: Que maravilhoso que é o rádio! É como a televisão, só que nem é preciso olhar! Bob Schulberg

A aparente falta de imagem no rádio longe de ser um defeito se apresenta como uma qualidade é o que diz o publicitário Bob Schulberg na citação acima e é o que outrora Bachelard nos lembrou quando mencionou que a falta da imagem do rádio não se configura como uma desvantagem porque "a ausência é uma superioridade: é precisamente o eixo da intimidade, a perspectiva da intimidade que vai se abrir". ${ }^{3}$ Neste texto inserido dentro de um Congresso Internacional de Teatro (Teatro do grego theatron = lugar de onde se vê, público) irei tratar de algo que tem como característica a ausência da visualidade: o rádio, mais especificamente o radioteatro.

Mas, o que é radioteatro? No Brasil, o termo é utilizado de forma ambígua muitas vezes como sinônimo de radionovela ou radiodrama, outras como um gênero que abriga transmissões de dramas pelo rádio. Também são utilizados na literatura os termos drama radiofônico, teatro radiofônico, peças radiofônicas ou a

1 Comunicação apresentada no XVII Congreso Internacional de Teatro Iberoamericano y Argentino, realizado de 5 a 9 de agosto de 2008 em Buenos Aires. Organizado pelo Instituto de Historia del Arte Argentino y Latinoamericano "Luis Ordaz", Facultad de Filosofía y Letras de la Universidad de Buenos Aires.

${ }^{2}$ Aluna regular do PPGT - Mestrado em Teatro/ CEART-UDESC. Ingressa no PPGT em março de 2008, sob orientação do profa. Dra. Vera Collaço

${ }^{3}$ BACHELARD, Gaston. Devaneio e Rádio. IN: O direito de sonhar. 4a ed. RJ: Bertrand Brasil, 1994, p.179. 
grafia rádio-teatro. Opto por utilizar a expressão radioteatro como sendo um gênero que abarca todo tipo de dramatização radiofônica 4 . Fazem parte deste gênero: as radionovelas, transmissões de dramas divididos em vários capítulos com continuidade (um depende do anterior); os seriados, transmissões divididas em episódios (sem necessidade de continuidade); as peças completas ou programas de fim, transmissões de dramas completos em um único capítulo ou poucos capítulos; os comerciais, as dramatizações policiais, etc.

Eduardo Montagnari faz uma reflexão da possibilidade de se chamar teatro um elemento acústico "que dispensando o olhar, prescinde tanto da presença física do ator quanto da presença do espectador", ${ }^{5}$ e apresenta os laços entre teatro e rádio:

Com efeito, ao ser elaborada a partir de uma forma de pensar oriunda do teatro, a linguagem do radioteatro recorre a determinadas fórmulas e recursos que, tendo por finalidade sanar a ausência dos elementos ópticos, ausentes no rádio, definem, por excelência, o espetáculo cênico: a voz de um narrador para informações cenográficas; a criação, por meios técnicos, de impressões espaciais coreográficas; a utilização da música como recheio para entreatos ou de peças musicais alegres, tristes, lentas ou movimentadas, para a criação dos "climas" de monólogos interiores ou para colorir prólogos, epílogos, cenas "pomposas" ou de multidões etc. ${ }^{6}$

Não obstante, o radioteatro é controverso. Pedro Barbosa em artigo denominado $O$ teatro radiofônico, esse outro equívoco ${ }^{7}$ afirma que um elemento exclusivamente sonoro, o rádio, não tem a ver com o teatro que é sonoro, espacial e presencial, de modo que o nome radioteatro estaria completamente equivocado. Certamente que o radioteatro não pretende ser teatro, pois se assim o fosse concordaria com Barbosa em sua afirmação de que este não seria nada mais que um teatro-cego. De fato, o radioteatro começou como um teatro-cego já que eram transmitidas peças teatrais seja captando os atores em uma

\footnotetext{
${ }^{4}$ Esta é também a opção do pesquisador Ricardo Medeiros, que tem várias publicações acerca do rádio em Santa Catarina.

5 (MONTAGNARI, Eduardo Fernando. Rádio e teatro: memória e possibilidades. Acta Scientiarum Human and Social Sciences. Maringá, v. 26, no. 1, p. 145-149, 2004. Disponível em:

<http://www.ppg.uem.br/docs/ctt/Humanas/2004_1/15_392_03_Eduardo\%20Montagnari_Radio\%2 0e\%20teatro.pdf>. Acesso em: 10 ago. 2007, p.145.

6 Idem, p.146.

7 BARBOSA, Pedro. O teatro radiofônico, esse outro equívoco. IN: Teorias do Teatro Moderno Axiomas e Teoremas. [São Paulo]: Edições Afrontamento, 1980.
} 
apresentação teatral, seja com atores em estúdio seguindo ipsis literis o texto dramatúrgico ou literário. Ou seja, o drama teatral transmitido pelas rádios como afirma Balsebre ${ }^{8}$ implicava em um fracasso comunicativo quando a simples transposição da cena para o "espaço auditivo" impedia ao radiouvinte ver o que foi criado para ser visto. No entanto, estas transmissões foram apenas os primeiros experimentos dentro da nova linguagem que estava sendo constituída.

Após as primeiras experiências com transmissões de peças dramatúrgicas e romances surgiu um novo elemento: o narrador. $O$ narrador contava ao ouvinte o que acontecia nos momentos de dramatização exclusivamente visuais. As rádios passaram então a transmitir textos (teatrais e romances) adaptados utilizando-se de narração e de uma orquestra (ou música) que interpretava breves melodias nas transições de cenas ou atos.

A fase seguinte do radioteatro se deu com A comedy of danger (1924), de Richard Hughes, considerada a primeira peça ${ }^{9}$ escrita expressamente para o meio radiofônico. A ação se passa em uma mina de carvão e a sonoplastia contém explosão, passos, barulho de água, efeito de eco, etc. E foi em SOS Rao-Rao-Foy (1928), de Friedrich Wolf, que foi utilizado pela primeira vez um recurso que ficaria famoso em A Guerra dos Mundos, transmitida por Orson Wells no ano 193810: a tematização de uma reportagem transmitida ao vivo. Uma data considerada decisiva em relação ao radioteatro é 1936 quando Marynowski, responsável do departamento dramático da Rádio Polônia, aboliu o uso da figura do narrador em todas as transmissões de radioteatro. ${ }^{11}$

Para além do uso de músicas e efeitos de sonoplastia, iniciou-se, principalmente na Alemanha - país que cunhou um termo próprio para radioteatro, Hörspiel, que abarca palavra, sonoplastia e música - estudos para uma "arte acústica", uma dramaturgia sonora, influenciados por Schaeffer, com seu conceito de paisagem sonora - conceito que foi ampliado posteriormente - e por Jonh Cage. O estudo de paisagens sonoras - abarcando agora não apenas sons gravados da natureza como era a proposta de Schaeffer, mas todos os tipos de

\footnotetext{
${ }^{8}$ BALSEBERE, Armand. El lenguaje radiofônico. $3^{\underline{a}}$ ed. Madrid: Cátedra, 2000.

9 Alguns pesquisadores consideram a peça $O$ Lobo, de Eugen Walter, 1922, transmitida pela Rádio WGY de Nova York, como a primeira peça radiofônica.

10 Para maiores informações sobre este episódio ver MEDITSCH, Eduardo (Org.). Rádio e Pânico: a Guerra dos Mundos, 60 anos depois. Florianópolis: Insular, 1998.

11 BALSEBERE, Op. cit.
} 
som trabalhados através de recursos tecnológicos de áudio como: eco, reverbe, fade, cross, inverse, scratch, etc. - ainda tem muito a contribuir tanto no radioteatro, que atualmente com a internet, celulares e podcast recebe novos campos de atuação, quanto ao próprio teatro que desde tempos imemoriais vem se transmutando e incorporando novas linguagens, novas poéticas.

Pavis (1996) considera o radioteatro (peça radiofônica) como estando a meio caminho entre a presença física do teatro e o espaço simbólico da página do romance, podemos observar uma esperança em relação ao destino do gênero: "Quando as pesquisas eletroacústicas se juntam às regras estritas da dramaturgia, por vezes resulta dessa união uma obra muito forte e original, o que prova que a literatura radiofônica já é um gênero estabelecido e com um futuro bastante promissor". ${ }^{12}$

No Brasil, o radioteatro teve seu esfacelamento ${ }^{13}$ com o término das transmissões de radionovelas e programas de fim. Segundo Luiz Alberto Sanz ${ }^{14}$ com o advento da televisão no país, acreditou-se estar o rádio defasado e não se investiu em novas tecnologias como, por exemplo, a estereofonia, o que contribuiu, além das razões políticas e financeiras, para o fim do radioteatro no país.

Alguns poucos pesquisadores brasileiros tem como foco o radioteatro. ${ }^{15} \mathrm{~A}$ própria história do rádio e linguagem radiofônica foi desprezada por muitos, como atesta Eduardo Meditsch "não produzimos quase nenhum conhecimento a respeito da linguagem do rádio, e sequer traduzimos o que o resto do mundo produziu", ${ }^{16}$ o que nos deixa, segundo ele, fora do debate internacional acerca do

\footnotetext{
${ }^{12}$ RÁDIO E TEATRO. IN: PAVIS, Patrice. Dicionário de Teatro. Trad.: J.Guinsburg e Maria Lúcia Pereira. São Paulo: Perspectiva, 1999, p.323.

13 O radioteatro ainda sobreviveu por alguns anos e ainda sobrevive em algumas rádios, principalmente nas formas de spots comerciais e esquetes cômicas, no entanto, não representam algo significativo e muitas vezes não abarcam estas novas experiências citadas.

${ }^{14}$ SANZ, Luiz Alberto. Dramaturgia da Informação Radiofônica. Rio de Janeiro: Gama Filho, 1999.

${ }^{15}$ Entre eles posso citar o trabalho, na área de Artes Cênicas, Mirna Spritezer da UFRGS, que além de pesquisar a história do radioteatro também trabalha com radioteatro na formação do ator, e Janete El Haouli, professora do Departamento de Música e Teatro da UEL que tem interesse por Espaço Sonoro e radioficções. Outro nome é Eduardo Montgnari, sociólogo, diretor e autor teatral e professor da Universidade Estadual de Maringáque apesar de não ter formação em teatro, atua na área, inclusive dirigiu uma peça teatral inspirada no radioteatro. Outros pesquisadores são da área de Comunicação, como Eduardo Meditsch e Valci Zucolloto, do curso de jornalismo da UFSC, que por vezes ministram a disciplina de Radioteatro. No jornalismo há também Ricardo Medeiros, já citado em outra nota. E ainda tem se pesquisadores, como Lia Calabre, na área da História; a grande maioria destes estudiosos, contudo, analisa o rádio como fator social e político. ${ }^{16}$ MEDITSCH, Eduardo. Sete meias-verdades e um lamentável engano... Universidade Federal de
} 
tema. Quero contribuir para a mudança deste panorama e espero que este texto desperte o desejo de outros para o mesmo. Atualmente, no Mestrado em Teatro (PPGT-UDESC) pesquiso o radioteatro romântico em Florianópolis. $\mathrm{Na}$ graduação, em Artes Cênicas, participei de um projeto de extensão (Cênicas na Rádio) que tinha como um dos objetivos a apresentação de peças de radioteatro através da rádio universitária (UDESC FM 100,1). Ainda acredito que este projeto possa ser expandido a ponto de se aliar as disciplinas, de voz, encenação, dramaturgia entre outras e ainda poder aglutinar outros cursos como a Música. Este é um dos meus sonhos, e "o rádio está verdadeiramente de posse de extraordinários sonhos acordados", já disse Bachelard ${ }^{17}$.

Santa Catarina, Florianópolis, 1995. Disponível em: <http://bocc.ubi.pt/pag/meditsch-eduardomeias-verdades.htm>. Acesso em: 10 mai. 2005, p.01.

17 Bachelard, Op. cit, p.181. 